\title{
Exposure source prevalence is associated with gender in hepatitis C virus patients from Rio de Janeiro, Brazil
}

\author{
Daniele Blasquez Olmedo', Patrícia Marraccini Precioso', António Lugdero-Correia', \\ Guida da Silva ${ }^{2}$, Angela Maria Guimarães dos Santos ${ }^{1}$, Luís Cristóvão Pôrto ${ }^{1 /+}$
}

'Universidade do Estado do Rio de Janeiro, Laboratório de Histocompatibilidade e Criopreservação, Rio de Janeiro, RJ, Brasil ${ }^{2}$ Secretaria Municipal de Saúde do Rio de Janeiro, Rio de Janeiro, RJ, Brasil

BACKGROUND Hepatitis $\mathrm{C}$ virus (HCV) infection is a worldwide public health problem. A characterisation of the differences in exposure sources among genders will enable improvements in surveillance actions.

METHODS Exposure data were obtained for 1180 confirmed HCV cases Brazil's mandatory reporting to epidemiological surveillance, which was directed by a reference laboratory in Rio de Janeiro, Brazil. The Chi-square test $(\chi 2)$ was used to assess the associations between exposure sources and gender. The prevalence ratio (PR) was calculated for exposures that showed an association.

RESULTS The results showed $57.7 \%$ cases were female, and associations with snorting drugs, sexual activity, surgery, aesthetic procedures, blood transfusions, and educational level were observed ( $\mathrm{p}<0.001)$. Men showed 2.53 (1.33-3.57), 4.83 (3.54-6.59), and 2.18 (1.33-3.57) times more exposure to sniffing drugs, risky sex and higher levels of education, respectively, than women. Women demonstrated 4.46 (3.21-6.21), 1.94 (1.43-2.63), and 3.10 (2.09-4.61) times more exposure to surgery, aesthetic procedures, and blood transfusions, respectively, than men.

CONCLUSION Our results showed differences in risk behaviours associated with gender among HCV carriers. These data are likely to significantly influence clinical practice regarding the adoption of specific approaches for counselling and control policies to prevent the emergence of new cases and break the chain of transmission of the virus.

Key words: risk behaviour - transmission - hepatitis C - epidemiological surveillance

Important variations have been observed in the epidemiology of the hepatitis $\mathrm{C}$ virus (HCV) infection, including the prevalence of distinct risk factors around the world (Lavanchy 2009, Gower et al. 2014, Cullen et al. 2015, El-Ghitany et al. 2015, Muñoz et al. 2015). Recently, Gower et al. (2014) found a global prevalence of anti-HCV seropositivity of 1.6\% (1.3-2.1\%) among all age groups, which corresponded to 115 (92-149) million cases of past viraemic infections. The viraemic prevalence (RNA positivity) was forecasted to be $1.1 \%(0.9$ $1.3 \%)$, corresponding to $80(64-103)$ million viraemic infections. Brazil ranked 8th among the countries that were studied (Gower et al. 2014).

Brazil is a continental country with a high geographical, social and cultural diversity. In a nationwide survey conducted in urban populations, the overall prevalence of anti-HCV seropositivity was $1.38 \%(1.12-1.64 \%)$, and predictors of HCV infections were shown to include older age, use of injected [odds ratio $(\mathrm{OR})=6.65 \%$ ] and inhaled $(\mathrm{OR}=$ $2.59 \%)$ drugs, hospitalisation $(\mathrm{OR}=1.90 \%)$, socially disadvantaged groups that lacked sewage disposal $(\mathrm{OR}=2.53)$, and the use of glass syringes $(\mathrm{OR}=1.52 \%)$. However, the

doi: 10.1590/0074-02760160553

Financial support: CAPES, FAPERJ

DBO was supported by a PhD scholarship from CAPES; LCP is supported by FAPERJ.

+ Corresponding author: Icporto@uerj.br

Received 27 December 2016

Accepted 17 April 2017 known risk factors explain less than $50 \%$ of the infected cases, limiting prevention strategies (Pereira et al. 2013). The Brazilian Information System for Notifiable Diseases (SINAN) provides data to the Health Ministry (MS 2012), which issues epidemiological reports that guide public policies. HCV infection is a notifiable disease in the SINAN (Naveira et al. 2014, MS 2015). In 2014, its seroprevalence was estimated to be 1.4 million cases in Brazil. The main route of transmission is parenteral (MS 2015). The case distributions by age group and gender observed in the Southeast (SE) suggested the existence of distinct parenteral exposure patterns between the genders.

The development of direct-acting antivirals (DAAs) has introduced a new reality to $\mathrm{HCV}$ infection. With the safety and efficacy achieved by new therapies (i.e., DAAs), the main solutions to HCV eradication involve prevention, control, and diagnosis (Hagan \& Schinazi 2013, Wedemeyer et al. 2014) which, when applied together, can substantially reduce $(>50 \%)$ the prevalence of $\mathrm{HCV}$ among high-risk individuals (Hagan et al. 2011, Martin et al. 2013). A good understanding of the routes of transmission is required to develop strategies to eliminate the HCV infection (Martin et al. 2013, Wedemeyer et al. 2014).

The World Health Organization (WHO 2000) recognises that there is a clear need for surveillance of transmissible diseases (TD), especially those with epidemic potential, such as HCV infection (Sharp et al. 2014, Seale et al. 2015). However, early detection should not be the only action of surveillance when the aim is its eradication. Recognising the main risk factors is essential, but recognising any exposure source pattern in those who carry the aetiologic agent can provide information regard- 
ing vulnerabilities to the appearance of secondary cases and can indicate possible fragilities in control systems. While some studies have sought to evaluate the exposure sources in men having sex with men (MHM) and people who inject drugs (PWID) (Martin et al. 2013, FernándezDávila et al. 2015, Marcellin et al. 2015), there is no direct evaluation of the exposure patterns that affect men and women that are important to individualised counselling and the disruption of the chain of transmission.

To assess which risk behaviours between genders may lead to continuous transmission of the HCV and develop recommendations for their management, we carried out a study of the association between exposure patterns in confirmed cases using data from mandatory notification.

\section{MATERIALS AND METHODS}

Subject enrolment and data collection - The present study was a descriptive, retrospective study of a series of cases that were followed for molecular $\mathrm{HCV}$ detection through viral load quantification and/or genotyping tests, which were performed at the Histocompatibility and Cryopreservation Laboratory of Rio de Janeiro State University (UERJ-HLA). The cases were considered as confirmed when the patient presented detectable $\mathrm{HCV}$ ribonucleic acid (RNA) or undetectable HCV-RNA through treatment. Non-confirmed cases were excluded from the study.

The data in the analysis were extracted from a database of all HCV cases submitted for laboratory surveillance from January 2013 to August 2015 at UERJ-HLA. The laboratory surveillance was conducted by a routine implemented as a new checkpoint for case notification control by the city of Rio de Janeiro Health Secretary. Briefly, patients with an HCV molecular test prescription that consented to participate were subjected to extensive epidemiological interviews that occurred before their blood collections. The data were registered on the official surveillance form of the Health Ministry used for case notification. The data entries were compiled in a customised Microsoft Access ${ }^{\circledR}$ database after data completeness revisions by the investigators. The form included socio-demographic data (age, gender, educational status, and self-declared skin colour), exposure sources throughout life or in the last six months, such as blood transfusion, transplantation, surgery and dental procedures (with bleeding), injectable medications administered with a glass syringe, inhalable and intravenous drugs, haemodialysis, acupuncture, tattooing, piercing, coinfection with human immunodeficiency virus (HIV), sexual activity (three or more sexual partners), other activities (related to nail care and barbers or other sources), accidents with biological materials, HCV viral load, and genotype. Information about hepatitis A virus (HAV) and hepatitis B virus (HBV) vaccinations was also collected through self-reports. Treatment status data were included in the forms.

Statistical analysis - Descriptive statistics were generated for the socio-demographic characteristics and exposure sources. Continuous variables were reported as the mean \pm standard deviation (SD) or median [interquartile range (IQR), minimum-maximum], and the Chi-square test $\left(\chi^{2}\right)$ for independence was used to assess the association of categorical variables and exposure source status. The prevalence ratio (PR) of each exposure source that demonstrated an association with gender was calculated with $95 \%$ confidence intervals $(95 \%$ $\mathrm{CI})$ and stratified by two age groups: less than or equal to 45 years of age $(\leq 45)$ and over 45 years of age $(>45)$. Multivariate analysis was performed using a binary logistic regression model when a variable in the univariate model had a $p$-value $<0.20$. The results were considered statistically significant when $\mathrm{p} \leq 0.05$. The statistical analyses were performed using the Statistical Package for the Social Sciences (SPSS for Windows, release 17.0; SPSS Inc., Chicago, IL, USA).

Ethical issues - The ethics committee of the Hospital Universitário Pedro Ernesto (HUPE) 139 approved the study protocol $\left(\mathrm{n}^{\mathrm{o}}\right.$ 1.274.583). The procedures followed were in accordance with the ethical standards of the Helsinki Declaration (2008).

\section{RESULTS}

Demographic characteristics of the interviewed $\mathrm{HCV}$ patients - A total of 4,897 patients were tested for HCVRNA detection from January 2013 to August 2015 at the UERJ-HLA. Patients were interviewed at the first confirmatory test for HCV-RNA (78.9\%), but many patients were interviewed during the monitoring of treatment or post-treatment evaluation. A total of 1,541 patients with suspected HCV agreed to answer the questionnaire and received an epidemiological interview, and 1,180 were confirmed cases. The characteristics of the confirmed HCV cases are shown in Table I. In all, $57.7 \%$ of the cases were female. The median age was 58 years (IQR 0-87), and there was no statistically significant difference between the mean ages of the males and females. Individuals who were $46-60$ years of age comprised $45.1 \%$ of the cases $(532 / 1180)$. There was no difference in the gender proportions within the age groups ( $\mathrm{p}=0.53$, data not shown).

Individuals of mixed and white self-declared colour/ race were the major groups, representing $73.1 \%$ of the cases. Only $11.6 \%$ of the HCV cases had at least 12 years of education. HCV genotype 1 was present in $88.2 \%$ of the cases, and in those who were treatment-naive (827), the mean viral load was $5.7( \pm 1.0) \mathrm{Log} \mathrm{IU} / \mathrm{mL}$.

The associations of exposure sources among the $H C V$ cases in the univariate analysis - Table II shows the history of exposure sources among the cases. The most prevalent exposure sources among the confirmed cases were dental and surgical treatment (93.5\% and 82.4\%). Exposure to sniffing drugs, illicit intravenous drugs, sexual activity, surgical treatment, blood transfusion, other exposures and HIV coinfection exhibited gender differences $(p<0.001)$. Exposures to inhaled drugs, injectable drugs, and sexual activity were 3.91, 4.52, and 2.15 times more prevalent, respectively, in males compared to females. In contrast, surgical procedures, other exposures, and blood transfusions were more prevalent in women by 1.28-, 1.39- and 1.62-fold, respectively. Exposure to HIV coinfection was excluded from the analysis of prevalence ratios because the amount of missing information was high (Table III). 
TABLE I

Characteristics of the hepatitis C virus (HCV) cases from January 2013 to August 2015

\begin{tabular}{|c|c|c|c|c|c|}
\hline Characteristics & $\mathrm{N}$ & $(\%)$ of total & Lower & Upper & $\mathrm{p}$ value \\
\hline \multicolumn{6}{|l|}{ Sex } \\
\hline Female & 681 & 57.7 & 54.9 & 60.5 & \\
\hline Male & 499 & 42.3 & 39.5 & 45.1 & $<0.001$ \\
\hline \multicolumn{6}{|l|}{ Ethnicity mixed } \\
\hline & 508 & 43.0 & 40.2 & 45.9 & \\
\hline White & 355 & 30.0 & 27.5 & 32.7 & \\
\hline Black & 298 & 26.0 & 22.8 & 27.8 & \\
\hline Native Brazilian/Oriental & 11 & 0.9 & 0.5 & 1.6 & \\
\hline Missing & 8 & 0.1 & 0.3 & 1.3 & $<0.001$ \\
\hline \multicolumn{6}{|l|}{ Educational level } \\
\hline Basic level (< 10 yr) & 627 & 53.2 & 50.3 & 56.0 & \\
\hline Medium level (10 to $12 \mathrm{yr}$ ) & 387 & 32.8 & 30.2 & 35.5 & \\
\hline Higher level (> 12 yr) & 137 & 11.6 & 9.9 & 13.6 & \\
\hline Missing & 29 & 2.4 & 1.7 & 3.5 & $<0.001$ \\
\hline \multicolumn{6}{|l|}{ Age group* } \\
\hline$>75$ & 32 & 3.0 & 1.9 & 3.80 & \\
\hline $61-75$ & 402 & 34.0 & 31.4 & 36.8 & \\
\hline $46-60$ & 532 & 45.0 & 42.3 & 47.9 & \\
\hline $31-45$ & 154 & 13.0 & 11.2 & 15.1 & \\
\hline $16-30$ & 35 & 2.9 & 2.1 & 4.1 & \\
\hline \multirow[t]{2}{*}{$<15$} & 25 & 2.1 & 1.4 & 3.1 & $<0.05$ \\
\hline & Mean & SD & & & \\
\hline HCV viral-load (log IU/mL) & 5.7 & 1.0 & & & \\
\hline \multicolumn{6}{|l|}{ Genotypes $(G) n=718$} \\
\hline G1 & 619 & 86.2 & 83.5 & 88.5 & \\
\hline $\mathrm{G} 2$ & 15 & 2.2 & 1.3 & 3.4 & \\
\hline G3 & 78 & 10.8 & 8.8 & 13.3 & \\
\hline G4 & 6 & 0.8 & 0.4 & 1.8 & $<0.001$ \\
\hline
\end{tabular}

*: age group by interquartile range (IQR); median age 58 (0-87) and mean age standard deviation (SD): 55.05 (13.84). yr: years; $\mathrm{N}$ : number of cases; IU/mL: international units by milliliters statistically significant when $\mathrm{p} \leq 0.05$.

TABLE II

Exposure sources of the histocompatibility and cryopreservation laboratory of Rio de Janeiro State University (UERJ-HLA) hepatitis C virus (HCV) cases interviewed from January 2013 to August 2015

\begin{tabular}{|c|c|c|c|c|c|c|c|}
\hline \multirow[b]{2}{*}{ Exposure sources** } & \multicolumn{2}{|c|}{ Male } & \multicolumn{2}{|c|}{ Female } & \multicolumn{2}{|c|}{ Total } & \multirow[b]{2}{*}{$\mathrm{p}$} \\
\hline & $\mathrm{N}$ & $(\%)$ & $\mathrm{N}$ & $(\%)$ & $\mathrm{N}$ & $(\%)$ & \\
\hline \multicolumn{8}{|l|}{ Injectable medication } \\
\hline Yes & 348 & 69.7 & 456 & 67.0 & 804 & 68.1 & 0.657 \\
\hline No & 122 & 24.5 & 170 & 25.0 & 292 & 24.7 & \\
\hline Missing & 29 & 5.8 & 55 & 8.1 & 84 & 7.1 & \\
\hline \multicolumn{8}{|l|}{ Sniffing drugs } \\
\hline Yes & 163 & 32.7 & 57 & 8.4 & 220 & 18.6 & $<0.001$ \\
\hline No & 333 & 66.7 & 622 & 91.3 & 955 & 80.9 & \\
\hline Missing & 3 & 0.6 & 2 & 0.3 & 5 & 0.4 & \\
\hline \multicolumn{8}{|c|}{ Illicit intravenous drugs } \\
\hline Yes & 86 & 17.2 & 26 & 3.8 & 112 & 9.4 & $<0.001$ \\
\hline No & 410 & 82.2 & 653 & 95.9 & 1063 & 90.0 & \\
\hline Missing & 3 & 0.6 & 2 & 0.3 & 5 & 0.4 & \\
\hline
\end{tabular}




\begin{tabular}{|c|c|c|c|c|c|c|c|}
\hline \multirow[b]{2}{*}{ Exposure sources** } & \multicolumn{2}{|c|}{ Male } & \multicolumn{2}{|c|}{ Female } & \multicolumn{2}{|c|}{ Total } & \multirow[b]{2}{*}{$\mathrm{p}$} \\
\hline & $\mathrm{N}$ & $(\%)$ & $\mathrm{N}$ & $(\%)$ & $\mathrm{N}$ & $(\%)$ & \\
\hline \multicolumn{8}{|l|}{$\overline{\text { Sexual }}$} \\
\hline Yes & 340 & 68.1 & 217 & 31.9 & 557 & 47.2 & $<0.001$ \\
\hline No & 152 & 30.5 & 459 & 67.4 & 611 & 51.7 & \\
\hline Missing & 7 & 1.4 & 5 & 0.7 & 12 & 1.0 & \\
\hline \multicolumn{8}{|l|}{ Tattoo/piercing } \\
\hline Yes & 90 & 18.0 & 111 & 16.3 & 201 & 17.0 & 0.419 \\
\hline No & 406 & 81.4 & 568 & 83.4 & 974 & 82.5 & \\
\hline Missing & 3 & 0.6 & 2 & 0.3 & 5 & 0.5 & \\
\hline \multicolumn{8}{|l|}{ Acupunture } \\
\hline Yes & 69 & 13.8 & 103 & 15.1 & 172 & 14.6 & 0.571 \\
\hline No & 423 & 84.8 & 574 & 84.3 & 997 & 84.5 & \\
\hline Missing & 7 & 1.4 & 4 & 0.6 & 11 & 0.9 & \\
\hline \multicolumn{8}{|l|}{ Surgical treatment } \\
\hline Yes & 353 & 70.7 & 620 & 91.0 & 973 & 82.4 & $<0.001$ \\
\hline No & 145 & 29.1 & 60 & 8.8 & 205 & 17.4 & \\
\hline Missing & 1 & 0.2 & 1 & 0.1 & 2 & 0.1 & \\
\hline \multicolumn{8}{|l|}{ Dental procedures } \\
\hline Yes & 464 & 93.0 & 640 & 94.0 & 1104 & 93.5 & 0.388 \\
\hline No & 34 & 6.8 & 38 & 5.6 & 72 & 6.1 & \\
\hline Missing & 1 & 0.2 & 3 & 0.4 & 4 & 0.4 & \\
\hline \multicolumn{8}{|l|}{ Haemodialysis } \\
\hline Yes & 19 & 3.8 & 20 & 2.9 & 39 & 3.31 & 0.407 \\
\hline No & 479 & 96.0 & 660 & 96.9 & 1139 & 96.5 & \\
\hline Missing & 1 & 0.2 & 1 & 0.1 & 2 & 0.2 & \\
\hline \multicolumn{8}{|l|}{ Other } \\
\hline Yes & 271 & 54.3 & 524 & 76.9 & 795 & 67.3 & $<0.001$ \\
\hline No & 213 & 42.7 & 145 & 21.3 & 358 & 30.3 & \\
\hline Missing & 15 & 3.0 & 12 & 1.8 & 27 & 2.2 & \\
\hline \multicolumn{8}{|l|}{ Blood trasfusion } \\
\hline Yes & 173 & 34.7 & 386 & 56.7 & 559 & 47.3 & $<0.001$ \\
\hline No & 299 & 59.9 & 262 & 38.5 & 561 & 47.5 & \\
\hline Missing & 27 & 5.4 & 33 & 4.8 & 60 & 5.0 & \\
\hline Transplantation & & & & & & & 0.969 \\
\hline Yes & 6 & 1.2 & 8 & 1.2 & 14 & 1.1 & \\
\hline No & 492 & 98.6 & 670 & 98.4 & 1162 & 98.4 & \\
\hline Missing & 1 & 0.2 & 3 & 0.4 & 4 & 0.34 & \\
\hline \multicolumn{8}{|l|}{$\mathrm{ABM}^{*}$} \\
\hline Yes & 56 & 11.2 & 59 & 8.7 & 115 & 9.7 & 0.158 \\
\hline No & 430 & 86.2 & 598 & 87.8 & 1028 & 87.1 & \\
\hline Missing & 13 & 2.6 & 24 & 3.5 & 37 & 3.1 & \\
\hline \multicolumn{8}{|l|}{ HIV } \\
\hline Yes & 55 & 11.0 & 28 & 4.1 & 83 & 7.0 & $<0.001$ \\
\hline No & 320 & 64.1 & 470 & 69.0 & 790 & 66.9 & \\
\hline Missing & 124 & 24.8 & 183 & 26.9 & 307 & 26.0 & \\
\hline
\end{tabular}

*: accident with biologic material; **: exposure sources missing data: $3.42 \%(565 / 15955)$; N: number of cases; Chi-square test ( $\chi 2)$ was used to assess the association between exposure sources and gender. Statistically significant when $\mathrm{p} \leq 0.05$.

The exposure prevalence of inhaled and injectable drugs, blood transfusions, and sexual activity were also associated with gender in the $>45$-years-old age group. Men in the $>45$-years-old age group reported 4.72, 5.98, and 2.41 times more exposure to sniffing drugs, illegal intrave- nous drugs, and sexual activity, respectively, than women. Women in the same age group reported exposures to surgical procedures, other sources, and blood transfusions that were $1.27,1.38$, and 1.87 times higher, respectively, compared to men. The association of gender with exposure to 
TABLE III

Prevalence ratio (PR) of exposure sources between men and women infected with hepatitis C virus (HCV) by age group

\begin{tabular}{|c|c|c|c|c|c|}
\hline \multirow[b]{2}{*}{ Exposure sources } & \multicolumn{2}{|c|}{ Gender } & \multirow[b]{2}{*}{$\mathrm{N}$} & \multirow[b]{2}{*}{ PR $(95 \% \mathrm{CI})$} & \multirow[b]{2}{*}{$\mathrm{p}$ value } \\
\hline & Male (\%) & Female (\%) & & & \\
\hline Sniffing drugs & 74.1 & 25.9 & 220 & $3.91(2.96-5.17)$ & $<0.001$ \\
\hline$<=45$ & 60.0 & 40.0 & 40 & $1.89(1.07-3.36)$ & 0.025 \\
\hline$>45$ & 77.2 & 22.8 & 180 & $4.72(3.41-6.52)$ & $<0.001$ \\
\hline Illicit intravenous drugs & 76.8 & 23.2 & 112 & $4.52(2.96-6.91)$ & $<0.001$ \\
\hline$<=45$ & 63.6 & 36.4 & 11 & $2.21(0.66-7.34)$ & 0.181 \\
\hline$>45$ & 78.2 & 21.8 & 101 & $5.98(3.65-9.78)$ & $<0.001$ \\
\hline Sexual & 61.0 & 39.0 & 557 & $2.15(1.90-2.43)$ & $<0.001$ \\
\hline$<=45$ & 52.5 & 47.5 & 118 & $1.40(1.10-1.78)$ & 0.005 \\
\hline$>45$ & 63.3 & 36.7 & 439 & $2.41(2.08-2.79)$ & $<0.001$ \\
\hline Surgical & 36.3 & 63.7 & 973 & $1.28(1.21-1.36)$ & $<0.001$ \\
\hline$<=45$ & 37.2 & 62.8 & 148 & $1.33(1.09-1.62)$ & 0.002 \\
\hline$>45$ & 36.1 & 63.9 & 825 & $1.27(1.19-1.35)$ & $<0.001$ \\
\hline Other & 34.1 & 65.9 & 795 & $1.39(1.28-1.52)$ & $<0.001$ \\
\hline$<=45$ & 34.9 & 64.1 & 149 & $1.46(1.20-1.78)$ & $<0.001$ \\
\hline$>45$ & 33.9 & 66.1 & 646 & $1.38(1.25-1.52)$ & $<0.001$ \\
\hline Blood transfusion & 30.9 & 69.1 & 559 & $1.62(1.42-1.85)$ & $<0.001$ \\
\hline$<=45$ & 49.4 & 50.6 & 85 & $0.81(0.58-1.11)$ & 0.196 \\
\hline$>45$ & 27.6 & 72.4 & 474 & $1.87(1.60-2.18)$ & $<0.001$ \\
\hline
\end{tabular}

$\mathrm{N}$ : number of cases. PR was calculated with $95 \%$ confidence intervals $(95 \% \mathrm{CI})$. Statistically significant when $\mathrm{p} \leq 0.05$.

surgical treatment and "other" sources was observed in both age groups $(\mathrm{p}<0.001)$, as shown in Table III.

The education level was independently associated with gender, demonstrating a linear association $(\mathrm{p}<$ 0.05 ). The basic level was reported to be 1.33 times more for women than men, and the higher education level was 2.45 times higher in men than women (Table IV).

The associations of exposure sources among the $\mathrm{HCV}$ cases by multivariate analysis - In the multivariate analysis, the prevalence of injectable drug use and basic education level lost their association to gender, suggesting that other factors may have acted as confounders in the univariate analysis. Exposures to inhaled drugs and sexual activity remained with a higher prevalence in men and were 2.53- and 4.83-fold higher, respectively, in men than women (Table V). Exposures to surgical treatment, other sources and blood transfusion were 4.46-, 1.94-, and 3.10fold higher, respectively, in women than men.

\section{DISCUSSION}

Parenteral exposure is multifaceted and depends mainly on individual risk behaviours. Factors that remain unchanged across time, such as gender, provide evidence for the validity of the statistical associations.
The official government data show that the total number of infected men reported to SINAN was greater than the number of women. However, their HCV detection rates were very similar, and the gender ratio decreased from 2008 to 2012, when it was 1.2 to 0.9 (each case in men was compared to 1 case of disease in women) (SES/RJ 2014). The 1:3 ratio found in this study may indicate a change in the sex ratio. Nevertheless, the gender proportion observed herein was similar to that observed in the $\mathrm{SE}$ region in a national survey, where women were predominant (57.7\%) (Pereira et al. 2013).

In our study, the method used for the data collection permitted a low loss of exposure data $(3.42 \%)$. The data integrity enabled the identification of the main exposure sources reported by a case series in the following order: dental and surgical procedures, injectable medications, other exposures, sexual risk behaviour, and blood transfusions. However, the frequency of exposure to some risk factors for $\mathrm{HCV}$ was more heavily reported by one gender than the other, suggesting a difference between exposure sources. Recognition of these sources can be essential to improving the actions of targeted epidemiological surveillance because knowledge of risk factors is not enough to ensure attitude. 
TABLE IV

Difference of educational level among the cases according gender

\begin{tabular}{lcccccc}
\hline & \multicolumn{3}{c}{ Gender } & & & \\
\cline { 2 - 3 } Educational level & Male (\%) & Female (\%) & & N & PR (95\% CI) & p value \\
\hline Basic level & 44.5 & 59.5 & 627 & $1.33(1.19-1.50)$ & $<0.001$ \\
Medium level & 33.9 & 32.0 & 387 & $1.05(0.89-1.24)$ & 0.502 & $<0.001$ \\
Higher level & 17.6 & 7.2 & & 137 & $2.45(1.76-3.40)$ & $<0.0$ \\
\hline
\end{tabular}

PR: prevalence ratio; N: number of cases. PR was calculated with $95 \%$ confidence intervals (95\% CI). Statistically significant when $\mathrm{p} \leq 0.05$.

\section{TABLE V}

Multivariate analysis of the Histocompatibility and Cryopreservation Laboratory of Rio de Janeiro State University (UERJ-HLA) hepatitis C virus (HCV)-infected cases reported to Brazilian Information System for Notifiable Diseases (SINAN) from January/2013 to August/2015

\begin{tabular}{|c|c|c|c|c|}
\hline \multirow[b]{2}{*}{ Variables } & \multicolumn{4}{|c|}{ Prevalence ratio (PR) } \\
\hline & Male & Female & $95 \% \mathrm{CI}$ & $\mathrm{p}$ \\
\hline \multicolumn{5}{|l|}{ Exposure sources } \\
\hline Sniffed drugs & 2.53 & 1 & $1.57-4.10$ & $<0.001$ \\
\hline Illicit intravenous drugs & 1.52 & 1 & $4.83-3.54$ & 0.208 \\
\hline Sexual & 4.83 & 1 & $3.54-6.59$ & $<0.001$ \\
\hline Surgical & 1 & 4.46 & $3.21-6.21$ & $<0.001$ \\
\hline Other & 1 & 1.94 & $1.43-2.63$ & $<0.001$ \\
\hline Blood transfusion & 1 & 3.10 & $2.09-4.61$ & $<0.001$ \\
\hline \multicolumn{5}{|l|}{ Educational level } \\
\hline Basic level & 1 & 1.16 & $0.85-1.60$ & 0.340 \\
\hline Higer level & 2.18 & 1 & $1.33-3.57$ & 0.002 \\
\hline
\end{tabular}

The independent association among variables, with respect to gender, was evaluated by logistic regression in order to confirm the profile of differential exposure found among the confirmed HCV cases. Multivariate analysis was performed using a binary logistic regression model when a variable in the univariate model had a p-value $<0.20$. Statistically significant when $\mathrm{p} \leq 0.05$.

In Brazil, extreme poverty, advanced age and injectable drugs are risk factors for $\mathrm{HCV}$, but not education. However, poor education is a risk factor in the Egyptian population (Pereira et al. 2013, El-Ghitany et al. 2015). We found an association between education and HCV infection in relation to gender. Cases that had a higher level of education (> 12 years) were less common (11.6\%), but there was a higher prevalence in males when analysed with other variables, where the prevalence in males was twice that observed in women. The high prevalence of cases among persons with basic and higher educational levels suggests that a clear and accessible approach should be considered in prevention and control policies.

Worldwide, people who inject drugs are known to have a high risk for HCV infection, as do blood transfusion recipients. On the other hand, the extent of this risk exposure may be under-reported due to stigmatisation and general confounders (Marinho \& Barreira 2013). There was no higher exposure to the parenteral transmission sources that are most commonly associated with risk (Marcellin et al. 2015, Muñoz et al. 2015), such as drug use (inhalable $=18.6 \%$; injectable $=9.4 \%$ ), and the prevalence for exposure to blood transfusions (47.3\%) was similar to that for sexual risk behaviour $(47.2 \%)$, which has already been noted (Pereira et al. 2013).

The published data on sexual and intra-family transmission are inconsistent (Cavalheiro 2007). Sexual behaviour with multiple sexual partners and the increased risk levels in specific groups, such as HIV and HBV coinfected persons, sex workers, homosexuals, illicit drug users, and populations with clinically evident sexually transmitted infections (STIs) are common risk factors for $\mathrm{HCV}$ infection. The rate of $\mathrm{HCV}$ infection related to sexual transmission may range from zero to $27 \%$. However, a review by Cavalheiro (2007) concluded that the chances of transmission were low and almost nil. Intra-familial transmission is strongly implicated and thought to be a confounder due to sharing of personal hygiene items. In the United States, the Centers for Disease Control and Prevention (CDC 2012) estimated that between 20-25\% 
of the transmission indices were associated with sexual contact, although the worldwide figures fluctuate in different populations. In our investigation, the measure of sexual exposure was limited to the occurrence of sexual risk behaviour involving unsafe sexual practices with three or more partners. There was no evaluation regarding types of sexual intercourse (Fernández-Dávila et al. 2015). Further studies should be conducted in this area.

Limitations - This study has some limitations. First, compulsory notification of viral hepatitis has limited reliability even if collected through an interview. The loss of data can be minimised, but the stigma associated with $\mathrm{HCV}$ infection may limit the reliability of self-reported data (Marinho \& Barreira 2013). Second, a case series analysis cannot determine a temporal sequence of cause and effect. Analyses in case series are easy to perform but serve to formulate hypotheses about groups of interest. Here, it was notable that men and women infected with HCV differed in their epidemiological history regarding exposures to their risk factors for $\mathrm{HCV}$, but the correlations found do not imply causation. Third, a limited group analysis cannot represent the total population. Available information regarding the reference population indicates that there are 3,423 cases in the city and 6,162 in the state of RJ (SES/RJ 2014). This study was conducted in one city in Brazil, so the epidemiological conclusion may be very limited to exposure sources from a specific population even though it is based on known global risk factors for HCV infection. Finally, the high proportion of people who were 45 years of age or older represents the exposure profiles of baby boomers, and the exposure sources of these men and women cannot represent exposure sources in younger men and women.

Adults born between 1945 and 1965 are more likely to be diagnosed with the HCV infection if they received a blood transfusion before the introduction of $\mathrm{HCV}$ screening in 1992 (CDC 2012). Based on these data, the CDC and the Ministry of Health of Brazil established a control policy for blood and recommend testing for this age group (Naveira et al. 2014). As most of the patients in our analysis were older ( $>45$ years), our analysis may have been influenced by the high prevalence of cases in this age group.

Finally, our experience suggests that the harm reduction policy for men should focus on condom distribution, paraphernalia, and pipes for drug users, but for women, direct surveillance information regarding the safety of surgical procedures, such as aesthetic procedures or the use of sharp blades, and blood transfusions should be a very useful and effective approach towards infection control. There is no doubt that for both genders, the empowerment of information regarding the main routes of transmission and the power of choice will create a range of opportunities for preventing and reducing infection in the population.

Conclusions - Our results showed differences in risk behaviour that was associated with gender among $\mathrm{HCV}$ carriers. The behaviours that expose individuals to known risk factors for $\mathrm{HCV}$ infection, such as drug use, blood transfusions, unprotected sex with multiple partners and surgical treatments, appear to be differentially associated with gender. The implementation of routine epidemiological interviews and counselling following notification may be helpful to support the surveillance of HCV and provide information for population studies. Knowledge of these risk behaviours should contribute to the eradication of the disease through prevention and control to break the chain of virus transmission.

\section{ACKNOWLEDGEMENTS}

To all the interviewers who participated in the data collection. We thank Brazil Health Ministry - Departamento de DST, AIDS e Hepatites Virais, for providing reagents and kits for the diagnostic tests.

\section{AUTHORS' CONTRIBUTION}

DBO - Designed the study, collected data, performed the statistical analysis and drafted the manuscript; PMP - collected and analysed the data; ALCJ and AMGS - carried out the molecular genetic tests and revised the manuscript; GS - participated in searching for the data collection and revised the manuscript; LCP - designed the study, drafted and revised the manuscript, and coordinated the laboratory work. All authors approved the final manuscript.

\section{REFERENCES}

Cavalheiro NP. Sexual transmission of hepatitis C. Rev Inst Med Trop Sao Paulo. 2007; 49(5): 271-7.

CDC - Centers for Disease Control and Prevention. Recommendations for the identification of chronic hepatitis $\mathrm{C}$ virus infection among persons born during 1945-1965. 2012. Available from: http://www.cdc.gov/mmwr/preview/mmwrhtml/rr6104a1.htm.

Cullen KJ, Hope VD, Croxford S, Shute J, Ncube F, Parry JV. Factors associated with recently acquired hepatitis $C$ virus infection in people who inject drugs in England, Wales and Northern Ireland: new findings from an unlinked anonymous monitoring survey. Epidemiol Infect. 2015; 143(7): 1398-407.

El-Ghitany EM, Wahab MMA, El-Wahab EWA, Hassouna S, Farghaly AG. A comprehensive hepatitis $\mathrm{C}$ virus risk factors meta-analysis (1989-2013): do they differ in Egypt? Liver Int. 2015; 35(2): 489-501.

Fernández-Dávila P, Folch C, Ferrer L, Soriano R, Diez M, Casabona J. Hepatitis $C$ virus infection and its relationship to certain sexual practices in men-who-have-sex-with-men in Spain: results from the European MSM Internet Survey (EMIS). Enferm Infecc Microbiol Clin. 2015; 33(5): 303-10.

Gower E, Estes C, Blach S, Razavi-Shearer K, Razavi H. Global epidemiology and genotype distribution of the hepatitis $\mathrm{C}$ virus infection. J Hepatol. 2014; 61(Suppl. 1): 545-57.

Hagan H, Pouget ER, des Jarlais DC. A systematic review and metaanalysis of interventions to prevent hepatitis $\mathrm{C}$ virus infection in people who inject drugs. J Infect Dis. 2011; 204(1): 74-83.

Hagan LM, Schinazi RF. Best strategies for global HCV eradication. Liver Int. 2013; 33(Suppl. 1): 68-79.

Lavanchy D. The global burden of hepatitis C. Liver Int. 2009; 29(Suppl. 1): 74-81.

Marcellin F, Lorente N, Demoulin B, Carrieri MP, Suzan-Monti M, Roux $\mathrm{P}$, et al. Comparison of risk factors in HIV-infected men who have sex with men, coinfected or not with hepatitis $C$ virus (ANRS VESPA2 French cross-sectional national survey). Sex Transm Infect. 2015; 91(1): 21-3.

Marinho RT, Barreira DP. Hepatitis C, stigma and cure. World J Gastroenterol. 2013; 19(40): 6703-9. 
Martin NK, Hickman M, Hutchinson SJ, Goldberg DJ, Vickerman P. Combination interventions to prevent $\mathrm{HCV}$ transmission among people who inject drugs: modeling the impact of antiviral treatment, needle and syringe programs, and opiate substitution therapy. Clin Infect Dis. 2013; 57(Suppl. 2): S39-45.

MS - Ministério da Saúde. Boletim epidemiológico hepatites virais. Ano III, No 01. 2012. Available from: http://www.aids.gov.br/ sites/default/files/anexos/publicacao/2012/51820/boletim epidemiol_gico_hepatites_virais_2012_ve_12026.pdf.

MS - Ministério da Saúde. Boletim epidemiológico hepatites virais. Ano IV, $N^{o}$ 01. 2015. Available from: http://www.aids.gov.br/sites/ default/files/anexos/publicacao/2015/58210/_p_boletim_hepatites_final_web_pdf_p__16377.pdf.

Muñoz F, Burgos JL, Cuevas-Mota J, Teshale E, Garfein RS. Individual and socio-environmental factors associated with unsafe injection practices among young adult injection drug users in San Diego. AIDS Behav. 2015; 19(1): 199-210.

Naveira M, Barbosa J, Sereno L, Domanico A, Mesquita F, de Souza LA. 12 years of universal access to hepatitis C treatment: Brazil's comprehensive response. J Int Assoc Provid AIDS Care. 2014; 13(6): $560-7$

Pereira LM, Martelli CM, Moreira RC, Merchan-Hamman E, Stein AT, Cardoso MR, et al. Prevalence and risk factors of hepatitis
C virus infection in Brazil, 2005 through 2009: a cross-sectional study. BMC Infect Dis. 2013; 13: 60.

Seale H, Chughtai AA, Kaur R, Crowe P, Phillipson L, Novytska Y, et al. Ask, speak up, and be proactive: Empowering patient infection control to prevent health care-acquired infections. Am J Infect Control. 2015; 43(5): 447-53.

SES/RJ - Secretaria de Estado de Saúde do Rio de Janeiro. Boletim epidemiológico DST/AIDS e hepatites virais 2014. 2014. Available from: http://www.riocomsaude.rj.gov.br/Publico/MostrarArquivo.aspx? $\mathrm{C}=\mathrm{sF} 6 \mathrm{igzRT} \% 2 \mathrm{Fp} 4 \% 3 \mathrm{D}$.

Sharp D, Palmore T, Grady C. The ethics of empowering patients as partners in healthcare-associated infection prevention. Infect Control Hosp Epidemiol. 2014; 35(3): 307-9.

Wedemeyer H, Duberg AS, Buti M, Rosenberg WM, Frankova S, Esmat $\mathrm{G}$, et al. Strategies to manage hepatitis $\mathrm{C}$ virus (HCV) disease burden. J Viral Hepat. 2014; 21(Suppl. 1): 60-89.

WHO - World Healt Organization. Department of communicable disease surveillance and response. WHO report on global surveillance of epidemic-prone infectious diseases. 2000. Available from: http://ghdx.healthdata.org/record/who-report-global-surveillance-epidemic-prone-infectious-diseases-2000. 